\title{
Investigation of Amorphous to Crystalline Phase Transition of Sodium Titanate by X-ray Absorption Spectroscopy and Scanning Transmission X-ray Microscopy
}

\begin{tabular}{|c|c|}
\hline Journal: & Canadian Journal of Chemistry \\
\hline Manuscript ID & cjc-2017-0132.R1 \\
\hline Manuscript Type: & Article \\
\hline Date Submitted by the Author: & 19-Mar-2017 \\
\hline Complete List of Authors: & $\begin{array}{l}\text { Liu, Jian; University of British Columbia, School of Engineering } \\
\text { Wang, Biqiong; The University of Western Ontario } \\
\text { Banis, Mohammad; The University of Western Ontario } \\
\text { Wang, Zhiqiang; Western University, Chemistry } \\
\text { Li, Ruying; The University of Western Ontario } \\
\text { Wang, Jian; Canadian Light Source Inc } \\
\text { Hu, Yongfeng; Canadian Light Source } \\
\text { Sham, Tsun-Kong; Department of Chemistry, } \\
\text { Sun, Xueliang; The University of Western Ontario }\end{array}$ \\
\hline $\begin{array}{r}\text { Is the invited manuscript for } \\
\text { consideration in a Special } \\
\text { Issue?: }\end{array}$ & TK Sham \\
\hline Keyword: & $\begin{array}{l}\text { X-ray absorption spectroscopy, sodium titanate, phase transition, scanning } \\
\text { transmission X-ray microscopy }\end{array}$ \\
\hline
\end{tabular}


1 Investigation of Amorphous to Crystalline Phase Transition of Sodium Titanate by X-ray

3 Jian Liu, ${ }^{\mathrm{a}}$ Biqiong Wang, ${ }^{\mathrm{a}, \mathrm{b}}$ Mohammad N. Banis, ${ }^{\mathrm{a}}$ Zhiqiang Wang, ${ }^{\mathrm{b}}$ Ruying Li, ${ }^{\mathrm{a}}$ Jian Wang, $4 \quad$ Yongfeng $\mathrm{Hu}^{\mathrm{c}},{ }^{\mathrm{T}}$ Tsun-Kong Sham, ${ }^{\mathrm{b}}$ and Xueliang Sun ${ }^{\mathrm{a},{ }^{*}}$

$5{ }^{\text {a }}$ Department of Mechanical and Materials Engineering, University of Western Ontario, London,

6 Ontario N6A 5B9, Canada

$7 \quad{ }^{b}$ Department of Chemistry, University of Western Ontario, London, Ontario N6A 5B7, Canada

$8 \quad{ }^{\mathrm{c}}$ Canadian Light Source, 44 Innovation Boulevard, Saskatoon, Saskatchewan S7N 2 V3, Canada

9 * Corresponding author's email: xsun@eng.uwo.ca; Tel: 519 661-2111 Ext 87759; Fax: 519

$10 \quad 661-3020$

11

12

13

14

15

16

17

18

19 
21 Nanostructured sodium titanate has great potential for various applications, such as sodium-ion

22 batteries, photocatalysts and waste treatment. Understanding of the phase transition mechanism

23 in sodium titanate upon post annealing is fundamentally important in order to tune the structure,

24 morphology, and property for targeted applications. In this work, we adopted amorphous sodium

25 titanate grown on carbon nanotubes by an atomic layer deposition technique as a reference, and used X-ray absorption spectroscopy (XAS) and scanning transmission X-ray microscopy (STXM)

27 as well as high-temperature in-situ X-ray diffraction (XRD) technique to elucidate the phase transition mechanism of sodium titanate from amorphous to crystalline upon annealing from $25^{\circ} \mathrm{C}$ to $900{ }^{\circ} \mathrm{C}$. XAS and XRD analysis disclosed that anatase $\mathrm{TiO}_{2}$ first formed in the matrix of amorphous sodium titanate at $500{ }^{\circ} \mathrm{C}$, and then recrystallized into $\mathrm{Na}_{0.23} \mathrm{TiO}_{2}$ at $700{ }^{\circ} \mathrm{C}$ and $900{ }^{\circ} \mathrm{C}$. XAS studies also revealed the $\mathrm{Ti}$ atoms in sodium titanate were oxidized during

32 annealing process, and reached an oxidation state about $3.8+$ for $\mathrm{Na}_{0.23} \mathrm{TiO}_{2}$. The elevated annealing temperature increased the coordination number of $\mathrm{Ti}$ atoms and the crystallinity of

34 sodium titanate. STXM chemical map provided spatial information and visualized evidence on 35 the phase transition among amorphous sodium titanate, anatase $\mathrm{TiO}_{2}$, and $\mathrm{Na}_{0.23} \mathrm{TiO}_{2}$ in the 36 samples annealed at intermediate temperatures $\left(500{ }^{\circ} \mathrm{C}\right.$ and $\left.700{ }^{\circ} \mathrm{C}\right)$. This work provides a 37 comprehensive understanding on the evolution of sodium titanate, in terms of crystal structure, 38 electronic structure, chemical environment, and morphology, under different post annealing 39 conditions.

41 Keywords: sodium titanate, phase transition, X-ray absorption spectroscopy, scanning 42 transmission X-ray microscopy 
43

44 Nanostructured alkaline titanates have received considerable interest because of their potential 45 applications in sodium-ion batteries, ${ }^{1-3}$ photocatalysts, ${ }^{4-5}$ and cation exchangers in the treatment

46 of radioactive liquid waste. ${ }^{6}$ For example, sodium titanate (such as $\mathrm{NaTiO}_{2}, \mathrm{Na}_{2} \mathrm{Ti}_{3} \mathrm{O}_{7}$ and

$47 \mathrm{Na}_{2} \mathrm{Ti}_{6} \mathrm{O}_{12}$ ) has been recently reported to show reversible $\mathrm{Na}^{+}$storage capability, and thus was

48 promising low-voltage anode material for sodium-ion batteries. ${ }^{1-3}$ Amorphous sodium titanate

49 grown on carbon nanotubes maintained a discharge capacity of $100 \mathrm{mAh} \mathrm{g}^{-1}$ for 1,500 cycles in

50 sodium-ion batteries, due to the unique core/shell structure that facilated fast $\mathrm{Na}^{+}$and $\mathrm{e}^{-}$transport

51 during charge and discharge process. ${ }^{7}$ Nanosizing sodium titanate has been proven as an

52 effective approach to improve $\mathrm{Na}^{+}$storage capacity in sodium-ion batteries, due to the reduced

53 transport length for both $\mathrm{Na}^{+}$and $\mathrm{e}^{-3}$. Therefore, it is critically important to control the

54 morphology, phase, and structure of nanostructured sodium titanate, in order to optimize their

55 performance in targeted applications.

56

57 Alkaline hydrothermal (HT) method has been intensively used to prepare sodium titanate 58 nanostructure. This method involves the treatment of crystalline $\mathrm{TiO}_{2}$ in a concentrated aqueous $59 \mathrm{NaOH}$ solution under a HT condition at relatively low temperatures. ${ }^{8-10}$ The preparation 60 conditions (reaction temperature, duration, and post treatment) might result in HT-derived 61 sodium titanate with different compositions, crystal structures (bititanate $\left[\mathrm{Na}_{x} \mathrm{Ti}_{2-x} \mathrm{O}_{4}(\mathrm{OH})\right]$, 62 trititanates $\left[\mathrm{Na}_{x} \mathrm{Ti}_{2-x} \mathrm{Ti}_{3} \mathrm{O}_{7}\right.$ ), ${ }^{11,12}$ and morphologies (nanotube, nanoribbon, nanosheet, and 63 nanorod). ${ }^{8-12}$ Nevertheless, the correlation between preparation conditions and properties of 64 sodium titanate is still ambiguous in literatures, and no general rule is applicable to all cases so 65 far. Another challenge is the discrepancy in the phase transition behavior of the HT-derived 
66 sodium titanate during post treatment. ${ }^{13-15}$ For example, Zhu and co-works found that $\mathrm{NaHTi}_{3} \mathrm{O}_{7}$

67 nanotubes synthesized by the HT method underwent a gradual degradation at $300{ }^{\circ} \mathrm{C}$ and $500{ }^{\circ} \mathrm{C}$

68 respectively, and finally transformed into $\mathrm{Na}_{2} \mathrm{Ti}_{6} \mathrm{O}_{13}$ nanorods after heat treatment at $700{ }^{\circ} \mathrm{C}$. ${ }^{13}$

69 The phase transition mechanism was explained by the release of structural water in the interlayer

70 space in order for sodium titanate to take more stable configuration with low energy. ${ }^{13}$ Another

71 work by Sun and $\mathrm{Li}^{14}$ found that titanate nanotubes changed to $\mathrm{Na}_{2} \mathrm{Ti}_{9} \mathrm{O}_{19}$ during the thermal

72 treatment at $600{ }^{\circ} \mathrm{C}$, which then transformed into a mixture of $\mathrm{Na}_{2} \mathrm{Ti}_{6} \mathrm{O}_{13}$ and anatase $\mathrm{TiO}_{2}$ at

$73850{ }^{\circ} \mathrm{C}$. In-situ Raman analysis revealed that titanate nanotubes transformed to anatase $\mathrm{TiO}_{2}$ at

$74550{ }^{\circ} \mathrm{C}$, which recrystallized into $\mathrm{Na}_{2} \mathrm{Ti}_{6} \mathrm{O}_{13}$ and $\mathrm{Na}_{2} \mathrm{Ti}_{3} \mathrm{O}_{7}$ at $800{ }^{\circ} \mathrm{C} .{ }^{15}$ Nevertheless, the phase

75 transition mechanism remains controversial, and might be related to the chemical composition of

76 different titanates made under different operating conditions and possible impurity residual as a

77 result of incomplete removal during washing process. Therefore, it is highly desirable to use

78 sodium titanate sample with controlled composition and free of impurity, in order to establish an

79 ideal reference for phase transition behavior study. Moreover, many previous work employed

80 tranditional X-ray techniques, such as X-ray diffraction (XRD), X-ray Raman scattering

81 spectroscopy, as main tools to investigate the phase transition in titanates. These techniques

82 collect averaged structure and phase information on a macroscopic level, and provide limited

83 information on the phase transition on a microscopic level.

84

85 In this work, we adopted sodium titanate prepared by an atomic layer deposition (ALD) 86 technique as a prototype for phase transition investigation. ${ }^{7}$ Different from the HT approach,

87 ALD deposits sodium titanate in a layer-by-layer manner, by using self-limiting and saturated

88 surface reactions. ${ }^{7}$ The composition of sodium titanate can be precisely controlled by adjusting 
89 the ALD subcycles of $\mathrm{NaO}^{\mathrm{t}}$ bu- $\mathrm{H}_{2} \mathrm{O}$ and TTIP- $\mathrm{H}_{2} \mathrm{O}{ }^{7}$ The complete ligand exchange reactions in 90 ALD processs avoid the introduction of impurites in sodium titanate. Therefore, sodium titanate 91 deposited by ALD presents an excellent candidate for the purpose of phase transition study. In 92 addition to tranditional XRD techniques, X-ray absorption spectroscopy (XAS) is used as a 93 poweful tool to investigate the electronic and crystal structure of sodium titanate subject to post 94 annealing, because it is sensitive to materials with and without long-range order. ${ }^{16,17}$ In 95 particular, X-ray absorption near-edge spectroscopy (XANES) provides local structure and 96 bonding information, such as oxidation state, coordinatin, and local symmetry, of the absorbing 97 atom, while extended X-ray absorption fine structure (EXAFS) yields information about the 98 interatomic distance and near neighbor coordination number. ${ }^{16}$ Moreover, scanning transmission 99 X-ray microscopy (STXM) is used to track the phase evolution and distribution in sodium 100 titanate under different annealing temperature. STXM developed using undulator based third101 generation synchrotron light source provides an exceptional capability for probing the electronic 102 structure and chemical speciation of an individual nanostructure with a nanoscale spatial 103 resolution. ${ }^{18}$ It can deliver combined information of XAS and X-ray microscopy, with a spectral 104 and spatial resolution of $0.05 \mathrm{eV}$ and $30 \mathrm{~nm}$, respectively, ${ }^{19}$ and therefore is ideal for elucidating 105 the phase transition mechanism of sodium titanate herein.

\section{2. Experimental}

\subsection{Preparaion of sodium titanates}

109 Sodium titanate was deposited on carbon nanotubes (CNTs) at $225^{\circ} \mathrm{C}$ in a Savannah 100 ALD 110 system (Ultratech/Cambridge Inc., USA) by following an ALD recipe developed previously. ${ }^{7}$ In 111 brief, sodium tert-butoxide $\left(\mathrm{NaO}^{\mathrm{t}} \mathrm{Bu}\right)$, titanium(IV) isopropoxide (TTIP), and distilled water 
$112\left(\mathrm{H}_{2} \mathrm{O}\right)$ were used as as ALD precursors. The source temperatures for $\mathrm{NaO}^{t} \mathrm{Bu}$ and TTIP were

$113185{ }^{\circ} \mathrm{C}$ and $85{ }^{\circ} \mathrm{C}$, respectively. These presursors were introduced sequentially into ALD

114 chamber in the order of $\mathrm{NaO}^{t} \mathrm{Bu}-\mathrm{H}_{2} \mathrm{O}-\mathrm{TTIP}-\mathrm{H}_{2} \mathrm{O}$ (one ALD cycle), with complete $\mathrm{N}_{2}$ gas puring

115 prior to each precursor. Sodium titanate was deposited on CNTs by simply repeating the above

116 ALD cycle.

$117 \quad 2.2$ Characterizations

118 High-temperature in-situ X-ray diffraction (XRD) measurement (Bruker D8 Advance, $\mathrm{Cu}-\mathrm{K} \alpha$ 119 X-ray source) was performed on sodium titanate/CNTs at $25{ }^{\circ} \mathrm{C}$ (as-deposited state), $500{ }^{\circ} \mathrm{C}$, $120700{ }^{\circ} \mathrm{C}$, and $900{ }^{\circ} \mathrm{C}$, respectively. At each temperature, the sample was annealed for $1 \mathrm{~h}$ before 121 the XRD pattern was measured. In-situ XRD measurement $\left(23^{\circ}-27^{\circ}\right.$, scan step of $0.02^{\circ}$ per 122 second) was further conducted on another sample at $900{ }^{\circ} \mathrm{C}$ with annealing time up to 300 min 123 until the complete phase transition from anatase $\mathrm{TiO}_{2}$ to crystalline $\mathrm{Na}_{0.23} \mathrm{TiO}_{2}$. The samples for 124 morphology and structure characterization were obtained by heat treatment of sodium 125 titanate/CNTs for $1 \mathrm{~h}$ in air at $500{ }^{\circ} \mathrm{C}, 700{ }^{\circ} \mathrm{C}$, and $900{ }^{\circ} \mathrm{C}$, which hereafter are denoted as NTO126 500, NTO-700, and NTO-900, respectively. The as-deposited sodium titanate on CNTs is 127 designated as NTO-25. The morphology of the samples were observed by field-emission 128 scanning electron microscope (SEM, Hitachi S4800) and transmission electron microscope 129 (TEM, Hitachi 7000). X-ray absorption near-edge spectroscopy (XANES) and extended X-ray 130 absorption fine structure (EXAFS) measurment was performed at the Canadian Light Source 131 (CLS) on the Spherical Grating Monochromator (SGM) beamline for Ti $\mathrm{L}_{3,2}$-edge spectrum and 132 on the hard X-ray microanalysis beamline with a premirror-double crystal monochromator-post 133 mirror configuration using $\mathrm{Si}$ (111) crystal and Rh mirror for Ti K-edge spectra. STXM 134 measurement was conducted at the soft X-ray spectromicroscopy (SM) beamline at CLS, which 
135 is equipped with a $25 \mathrm{~nm}$ outermost-zone zone plate (CXRO, Berkeley Lab). The diffraction136 limited spatial resolution for this zone plate is $30 \mathrm{~nm}$. Image sequence (stack) scans over a range 137 of photon energies were acquired for the same sample region at the $\mathrm{Ti}_{3,2}$-edge. Detailed 138 information about STXM sample preparation, data acquisition, and data analysis can be found 139 elsewhere. ${ }^{16,19}$

\section{Results and Discussion}

(a)

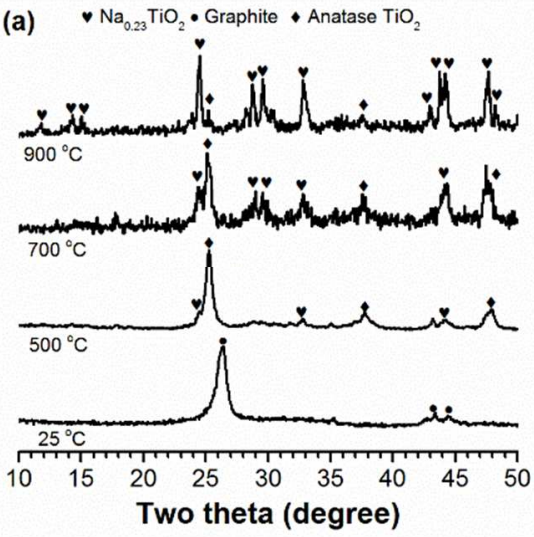

(b)

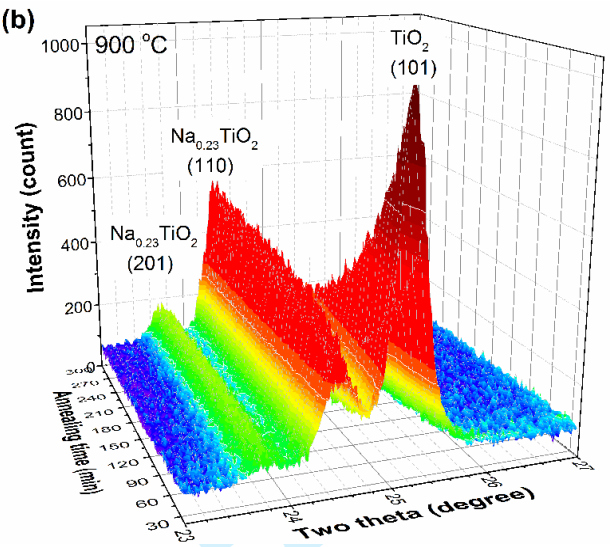

(c)

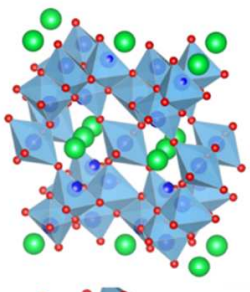

(d)

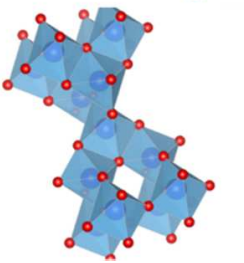

Figure 1. (a) XRD patterns of sodium titanates at $25^{\circ} \mathrm{C}$ (as-deposited) and in-situ annealed at

$\mathrm{Na}_{0.23} \mathrm{TiO}_{2}$ (JCPDS No. 22-1404) and (d) anatase $\mathrm{TiO}_{2}$ (JCPDS No. 02-0387) (red: oxygen; blue:

and $1 \mathrm{~b}$ were adapted from ref. [7] with permission from the Royal Society of Chemistry).

149 Sodium titanate was deposited on carbon nanotubes (CNTs) at $225^{\circ} \mathrm{C}$ by using an ALD process 
153 temperature in-situ XRD measurement was performed on the sodium titanate/CNTs in air, in 154 order to track the phase evolution from amorphous to crystalline sodium titanate. During the in155 situ XRD measurment process, the sample was annealed for $1 \mathrm{~h}$ at each temperature $\left(500{ }^{\circ} \mathrm{C}\right.$, $156700{ }^{\circ} \mathrm{C}$, and $900{ }^{\circ} \mathrm{C}$ ), before an in-situ XRD measurment was made between $10^{\circ}$ and $50^{\circ}$ at a 157 scanning rate of $0.02^{\circ}$ per second. As shown in Figure 1, the XRD pattern of sodium titanate 158 annealed at $500{ }^{\circ} \mathrm{C}$ is dominated by diffraction peaks from anatase $\mathrm{TiO}_{2}$ (JCPDS No. 02-0387), 159 with several weak peaks assignable to monoclinic $\mathrm{Na}_{0.23} \mathrm{TiO}_{2}$ (JCPDS No. 22-1404). The 160 diffraction peaks of CNTs disappear in the sample annealed at $500{ }^{\circ} \mathrm{C}$, due to the combustion of 161 CNTs in air. Once the temperature is elevated to $700{ }^{\circ} \mathrm{C}$, the peak intensity of anatase $\mathrm{TiO}_{2}$ 162 decreases while that of monoclinic $\mathrm{Na}_{0.23} \mathrm{TiO}_{2}$ increases, disclosing the gradual phase transition 163 from the former to the latter. At $900{ }^{\circ} \mathrm{C}$, the sodium tianate is mainly composed of monoclinic $164 \mathrm{Na}_{0.23} \mathrm{TiO}_{2}$, with the presence of minor diffraction peaks belonging to anatase $\mathrm{TiO}_{2}$ (Figure 1). 165 Another in-situ XRD measurment was conducted as a function of annealing time on sodium 166 titanate at $900{ }^{\circ} \mathrm{C}$, in order to find out the time needed to obtain pure monoclinic $\mathrm{Na}_{0.23} \mathrm{TiO}_{2}$. As 167 illustrated in Figure $1 \mathrm{~b}$, the (101) peak of anatase $\mathrm{TiO}_{2}$ gradually decreases in the intensity, while 168 the (110) peak of monoclinic $\mathrm{Na}_{0.23} \mathrm{TiO}_{2}$ undergoes the opposite trend, with the increase of 169 annealing time. It is found that 300-minute annealing is needed to complete the phase transition 170 from anatase $\mathrm{TiO}_{2}$ to monoclinic $\mathrm{Na}_{0.23} \mathrm{TiO}_{2}$. The XRD results in Figure 1 suggest that an 171 intermediate anatase $\mathrm{TiO}_{2}$ is formed in amorphous sodium titanate at a low temperature $\left(500{ }^{\circ} \mathrm{C}\right)$, 172 and recrytallizes to $\mathrm{Na}_{0.23} \mathrm{TiO}_{2}$ at temperatures higher than $700{ }^{\circ} \mathrm{C}$. The fact that anatase $\mathrm{TiO}_{2}$ 173 first forms in sodium titanate at relative low tempertures suggests the lower nucleation and 174 growth energy of anatase $\mathrm{TiO}_{2}$ than $\mathrm{Na}_{0.23} \mathrm{TiO}_{2}$ (their crystaline structures are illustrated in 175 Figure 1c and 1d). 

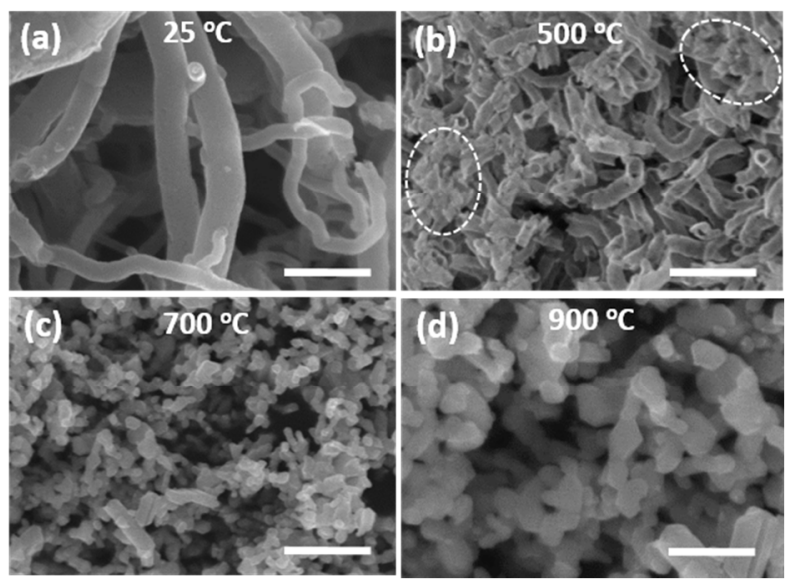

Figure 2. Morphology evolution of sodium titanate (a) as-deposited $\left(25^{\circ} \mathrm{C}\right)$, annealed at (b) $500{ }^{\circ} \mathrm{C}$, (c) $700{ }^{\circ} \mathrm{C}$, and (d) $900{ }^{\circ} \mathrm{C}$ in air, corresponding to the XRD patterns in Figure 1a. The scale bars in (a-d) represent $200 \mathrm{~nm}$.

182 Morphology evolution of sodium titanate with annealing temperature is examined by using 183 SEM, and the typical images are illustrated in Figure 2. At the as-deposited state, the sodium 184 titanate is uniformly covered on the surface of CNTs, forming a sodium titanate/CNTs shell/core 185 structure (Figure 2a). Annealing at $500{ }^{\circ} \mathrm{C}$ leads to the burning of CNTs in sodium titanate/CNTs, 186 creating hollow tubular structure (Figure 2b). Meanwhile, the hollow sodium titanate starts to 187 collapse locally at $500{ }^{\circ} \mathrm{C}$ (as highlighted in the Figure $2 \mathrm{~b}$ ), and totally breaks into nanoparticles 188 with size of $20-50 \mathrm{~nm}$ at $700{ }^{\circ} \mathrm{C}$ (Figure 2c). Further annealing at $900{ }^{\circ} \mathrm{C}$ results in the growth of 189 these nanoparticles into $100-150 \mathrm{~nm}$, as shown in Figure 2d. Figure 2 presents that with the 190 increase of annealing temperature, sodium titanate evolutes from shell/core structure to hollow 191 structure, and finally nanoparticles. 

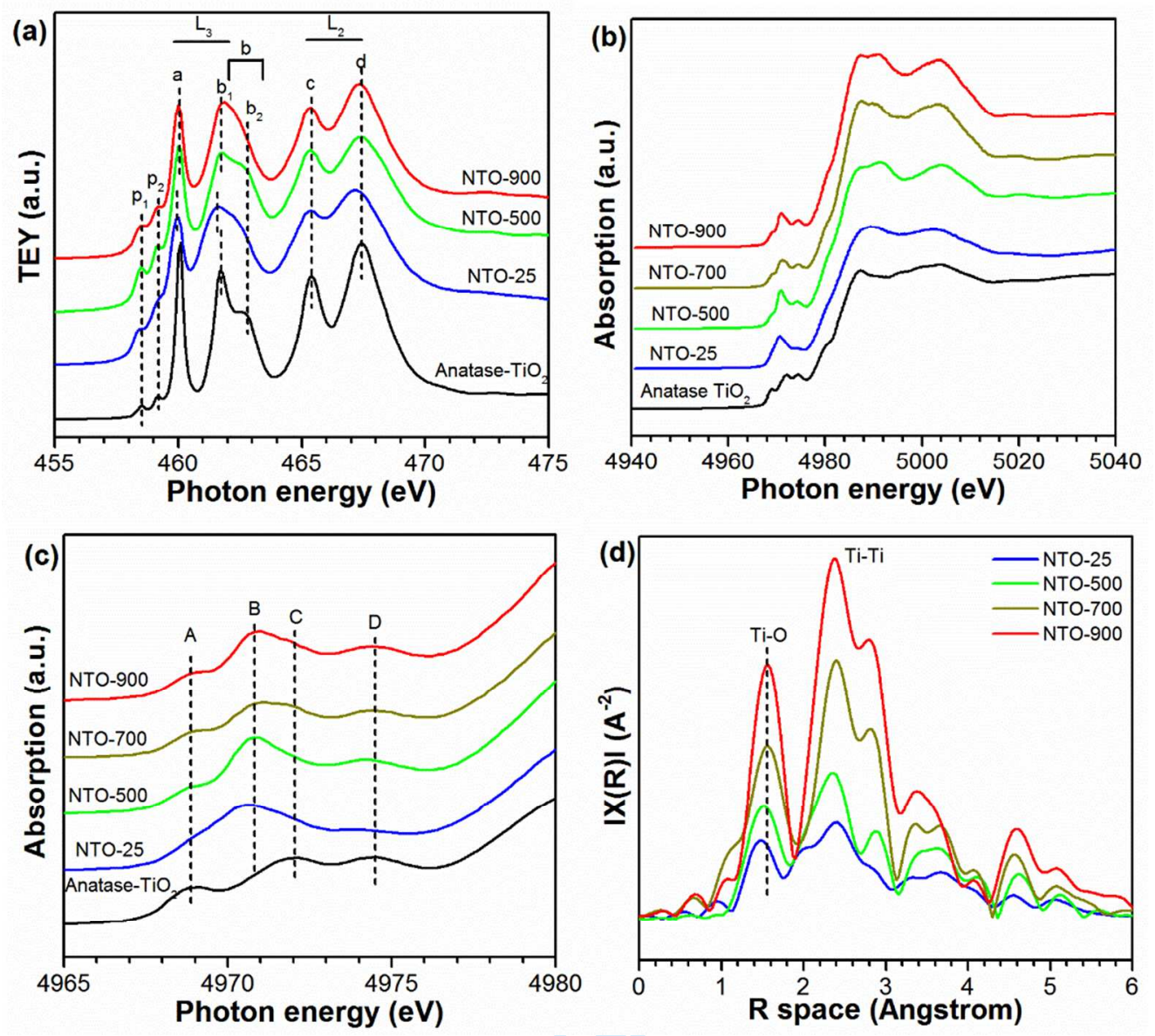

Figure 3. (a) Ti $\mathrm{L}_{3,2}$-edge in total electron yield (TEY), (b) Ti K-edge, (c) pre-edge region of Ti K-edge, and (d) R space XANES spectra of the as-deposited sodium titanate (NTO-25), and 197 sodium titanate annealed at $500^{\circ} \mathrm{C}(\mathrm{NTO}-500), 700^{\circ} \mathrm{C}(\mathrm{NTO}-700)$, and $900{ }^{\circ} \mathrm{C}(\mathrm{NTO}-900)$, in 198 comparsion to anatase $\mathrm{TiO}_{2}$.

199 XANES and EXAFS techniques are used to examine the chemical environment, electronic 200 structure, interatomic distance, and near neighbor coordination number of sodium titanate during 201 the phase transition. Figure 3 depicts the $\mathrm{Ti} \mathrm{L}_{3,2}$-edge (in total electron field (TEY) mode) and Ti 202 K-edge XANES spectra of the as-deposited sodium titanate and sodium titanate annealed at $203500^{\circ} \mathrm{C}, 700^{\circ} \mathrm{C}$, and $900^{\circ} \mathrm{C}$. Ti L ${ }_{3,2}$-edge spectra in fluorescence yield (FLY) (Figure SI-1) and 204 TEY mode the same spectral features. FLY gives bulk-sensitive information whereas TEY is 205 surface sensitive. From Ti $\mathrm{L}_{3,2}$-edge spectra in Figure $3 \mathrm{a}$ we can see that there are a couple of 
206

207

208

209

210

211

212

213

214

215

216

217

218

219

220

221

222

223

224

225

226

227

228

weak pre-edge shoulder peaks (marked as $\mathrm{p}_{1}$ an $\mathrm{p}_{2}$ ) at $458.5 \mathrm{eV}$ and $460.0 \mathrm{eV}$, followed by two series of strong resonances denoted as a, b, and $\mathrm{c}$, $\mathrm{d}$, for the apparent $\mathrm{L}_{3}$ and $\mathrm{L}_{2}$ edges, respectively. These spectral features are typical indication of $\mathrm{Ti}$ atoms in the distorted $\mathrm{TiO}_{6}$ octahedral structure..$^{20,21}$ In general, $\mathrm{p}_{1}$ and $\mathrm{p}_{2}$ at the pre-edge can be attributed to core hole-d electron coupling; peaks $\mathrm{a}, \mathrm{b}$ at the $\mathrm{Ti} \mathrm{L}_{3}$-edge are assigned to dipole excitation from $\mathrm{Ti} 2 \mathrm{p}_{3 / 2}$ state to $t_{2 g}$ and $e_{g}$ unoccupled states, respectively; $c$ and $d$ peaks at $\mathrm{Ti} \mathrm{L}_{2}$-edge to electronic transition from Ti $2 \mathrm{p}_{1 / 2}$ states to $\mathrm{t}_{2 \mathrm{~g}}$ and $\mathrm{e}_{\mathrm{g}}$ unoccupled states, respectively. ${ }^{16,17,20,21}$ For NTO-25, the $\mathrm{Ti} \mathrm{L}_{3,2}$-edge spectrum shows broadening feature compared to anatase $\mathrm{TiO}_{2}$ and NTO 900, reflecting the highly disordered and amorphous character in the as-deposited sodium titanate (NTO-25). ${ }^{21,22}$ Moreover, the a and $\mathrm{b}$ peaks for NTO-25 shift to a lower energy with $0.2 \mathrm{eV}$ compared to those of anatase $\mathrm{TiO}_{2}$ (Table SI-1), suggesting the reduction of $\mathrm{Ti}^{4+}$ in amorphous sodium titanate due to the introduction of $\mathrm{Na}$ ions. ${ }^{22}$ Turning our attention to NTO-500, the preedge peaks ( $p_{1}$ and $\left.p_{2}\right)$ and $L_{3}$-edge peaks $(a$ and $b)$ become more intense and well-resolved in contrast to NTO-25, and the splitting of $b$ peak into $b_{1}$ and $b_{2}$ peaks can be clearly identified. The $a$ and $b$ peaks of NTO-500 and NTO-900 shift to energy positions higher than those of NTO-25, but slightly lower than anatase $\mathrm{TiO}_{2}(\sim 0.1 \mathrm{eV})$, indicating the oxidation of $\mathrm{Ti}$ atoms in amorphous sodium titanate during the annealing process (Table SI-1). The relative intensity ratio of $\mathrm{b}_{1} / \mathrm{b}_{2}$ peaks is the spectral fringerprint of different types of $\mathrm{TiO}_{2}\left(\mathrm{I}_{\mathrm{b} 1} / \mathrm{I}_{\mathrm{b} 2}>1\right.$ for anatase $\mathrm{TiO}_{2}$, $\mathrm{I}_{\mathrm{b} 1} / \mathrm{I}_{\mathrm{b} 2}<1$ for rutile $\mathrm{TiO}_{2}$ ), and it has been well documented by experiment and theory. ${ }^{16,20}$ In Figure $3 a$, the intensity ratio and position of $b_{1}$ and $b_{2}$ peaks for NTO-500 follow a similar trend as those for anatase $\mathrm{TiO}_{2}$, indicating the formation of anatase $\mathrm{TiO}_{2}$ structure in NTO-500 (in agreement with the XRD finding in Figure 1a). It is noteworthy that $I_{b 1} / I_{b 2}$ of NTO-500 is relatively lower than that of anatase $\mathrm{TiO}_{2}$, and the $\mathrm{Ti} \mathrm{L}_{3}$-edge spectrum of NTO-500 bears the 
229 broadening feature of NTO-25. This comparsion suggests that amorphous sodium titanate still 230 remains in NTO-500. Therefore, NTO-500 mainly consists of anatase $\mathrm{TiO}_{2}$ and amorphous 231 sodium titanate. For $\mathrm{NTO}-900$, the $\mathrm{Ti} \mathrm{L}_{2}$-edge and $\mathrm{L}_{3}$-edge peaks show narrowed feature, 232 revealing a high crystallinity of sodium titanate annealed at $900{ }^{\circ} \mathrm{C}$. Moreover, the absence of $\mathrm{b}$ 233 peak splitting indicates that there is no significant tetragonal distortion in NTO-900, ${ }^{17}$ due to the 234 incorporation of $\mathrm{Na}$ ions in the monoclinic $\mathrm{Na}_{0.23} \mathrm{TiO}_{2}$ structure. Another notable difference 235 between NTO-900 and NTO-500 as well as anatase $\mathrm{TiO}_{2}$ is the relative lower intensity ratio of $236 \mathrm{a} / \mathrm{b}$ peak at $\mathrm{L}_{3}$-edge, which is reflective of the smaller crystal field in NTO-900 than in the 237 latters. ${ }^{17,21}$ The relative intensity of the $\mathrm{L}_{3}$-edge doublets a and $\mathrm{b}$ peaks is related to the strenght 238 of the crystal field. In general, the larger the crystal field, the more intense the peak a relative to 239 peak b. ${ }^{17} \mathrm{Ti} \mathrm{L}_{3,2}$-edge spectra analysis complements the finding on the phase transition pathway 240 of sodium titanate from in-situ XRD characterization. It also reveals that the oxidation state of Ti 241 atoms was lower than $4+$ in amorphous sodium titanate, and then slightly increased during 242 subsequent annealing process. In addition, $\mathrm{Ti} \mathrm{L}_{3,2}$-edge spectra analysis discloses the reduced 243 tetragonal distortion in NTO-900 compared with anatase $\mathrm{TiO}_{2}$ as a result of their structural 244 difference (Figures 1c, and 1d).

246 Ti K-edge feature is highly sensitive to local bonding environment of the targeted element, thus

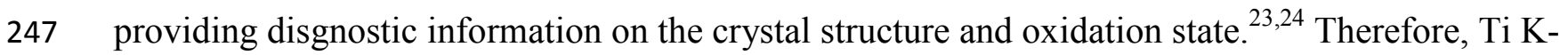
248 edge XANES analysis was further conducted on amorphous sodium titanate, NTO-500, NTO249 700, and NTO-900. The results are presented in Figure 3b. All the Ti K-edge spectra show 250 typical pre-edge feature and the white line. ${ }^{23-26}$ The edge region in the absorption spectra 251 provides clear information on the environment geometry and electronic structure of the 
252 absorption atom. ${ }^{23,24}$ In Figure 3b, the edge position (the peak maximum of the first derivative 253 function) of Ti-K edge spectra are determined to be $4978.9 \mathrm{eV}$ for NTO-25, $4979.1 \mathrm{eV}$ for NTO254 500, NTO-700 and NTO-900, and $4979.2 \mathrm{eV}$ for anatase $\mathrm{TiO}_{2}$ (as compared in Table SI-1). The 255 relative lower edge position of NTO-25 than anatase $\mathrm{TiO}_{2}$ is indicative of the oxidation state of 256 Ti atoms lower than $4+$ in the former, consistent with the conclusion drawn from $\mathrm{Ti} \mathrm{L}_{3,2}$-edge 257 spectra analysis (Figure 3a). The white line of NTO-900 has a slightly lower energy than anatase $258 \mathrm{TiO}_{2}$, due to a nominal $\mathrm{Ti}$ oxidation state of $\sim 3.8+$ in crystalline $\mathrm{Na}_{0.23} \mathrm{TiO}_{2}$. It should be 259 pointed out that in addition to the oxidation state, the change in Ti-O bond distance and crystal 260 structure can also affect the edge position of Ti K-edge. ${ }^{23}$ In Figure $3 \mathrm{c}$, the characteristic pre261 edge peaks (marked as A, B, C, and D) between $4965 \mathrm{eV}$ and $4973 \mathrm{eV}$ arise from quadrupole 262 transition and hybridization of $\mathrm{p}$ and $\mathrm{d}$ orbitals of the Ti atom and surrounding neighbors. ${ }^{23-26}$ 263 Although the interpretation of these pre-edge peaks is still ambiguous in literatures, the spectral 264 difference among anatase $\mathrm{TiO}_{2}$ and sodium titanates in the pre-edge region still can act as a 265 reference for identifying titanate structure in future. All the samples show one peak A at 4968.8 $266 \mathrm{eV}$, which is assigned to the quadrupole transition of $1 \mathrm{~s}$ to $\mathrm{t}_{2 \mathrm{~g}}$ states of octahedral $\mathrm{TiO}_{6}{ }^{22,23}$ The 267 relative intensity ratio between peak $\mathrm{B}$ and peak $\mathrm{C}$ is much higher in sodium titanate than in 268 anatase $\mathrm{TiO}_{2}$, The strongest peak B located at $4970.9 \mathrm{eV}$ appears to be a typical feature of 269 sodium titanate, and has been detected previously in sodium titanate nanoribbons. The peak D of 270 sodium titanate is nearly the same as anatase $\mathrm{TiO}_{2}$, and is attributable to the transition to $\mathrm{e}_{\mathrm{g}}$ band 271 state. $^{22,23}$ Fourier transformations (FT) of extended X-ray absorption fine structure (EXAFS) 272 spectra of sodium titanate are shown in Figure 3d. The change in the coordination number of $\mathrm{Ti}$ 273 atoms can be clearly observed in the FTs of Ti K-edge EXAFS (in R-space). In Figure 3d the 274 peaks located at about $1.6 \AA$ and $2.5 \AA$ correspond to Ti-O and Ti-Ti coordination shells, 
275 respectively. $^{22}$ The relative intensity tracks the cordination number and Debye-Waller factor 276 (disorder). Any static disorder will reduce the amplitude. All sodium titanates exhibit similar 277 EXAFS oscillations in the low R-region. But, noticeable higher magnitude is observed in the 278 sodium titanate annealed at a higher temperature, revealing a higher coordination number and/or 279 Debye-Waller factor on average of Ti atoms and hence an increase of crystallinity among them. ${ }^{22}$ 280 Moreover, NTO-900 exhibits a slightly larger R interatomic distance of Ti-O bond than the 281 others, probably due to the insertion of $\mathrm{Na}$ ions in the atomic structure, as seen in the crystal 282 structure of $\mathrm{Na}_{0.23} \mathrm{TiO}_{2}$ (Figure 1c). From Figure 3, it can be concluded that the elevated 283 annealing temperature increases the coordination number of $\mathrm{Ti}$ atoms and the crystallinity of 284 sodium titanate, and causes a slight increase in the Ti oxidation state.
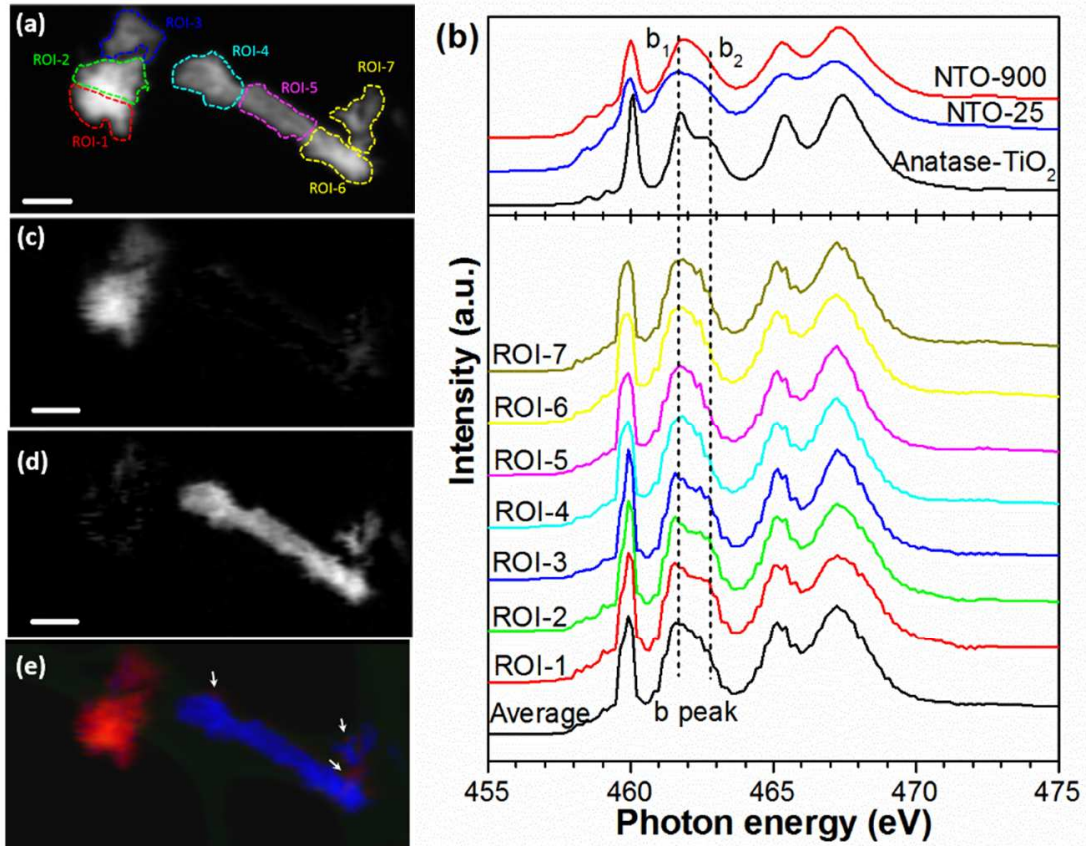

Figure 4. (a) STXM optical density image of NTO-500 (the image was averaged from all stack images at the Ti $\mathrm{L}_{3,2}$-edge); (b) Ti $\mathrm{L}_{3,2}$-edge XANES spectra extracted from different ROIs in (a) and together with an average spectrum (sum) of these ROIs in comparison with the TEY spectra of anatase $\mathrm{TiO}_{2}$, NTO-25, and NTO-900; STXM chemical maps of Ti in (c) anatase $\mathrm{TiO}_{2}$, 
(d) amorphous sodium titanate, and (e) composite map of $\mathrm{Ti}$ in anatase $\mathrm{TiO}_{2}$ (red) and amorphous sodium titanate (blue) (green is holy carbon). The scale bars in (a, c, d, and e) represent $500 \mathrm{~nm}$.

XANES analysis provides averaged spectrosopic information about the whole sample of sodium titanate, and no microscopic information could be extracted. In contrast, STXM measures absolute absorption of the specimen in transmission mode by using a nano-sized X-ray beam, and is a powerful technique to extract spectromicroscopic information on chemical map and corresponding absorption spectroscopic feature of an interested nanostructure. ${ }^{27,28}$ Therefore, STXM is adopted to analyze the phase and chemical distribution in NTO-500 and NTO-700, which have mixed phases of amorphous sodium titante, anatase $\mathrm{TiO}_{2}$ and/or crystalline $\mathrm{Na}_{0.23} \mathrm{TiO}_{2}$. Figure $4 \mathrm{a}$ shows a STXM optical density image of NTO-500 recorded at the Ti $\mathrm{L}_{3,2^{-}}$ edge (see corresponding TEM image of the same region in Figure SI-2a). Ti $\mathrm{L}_{3,2}$-edge XANES spectra collected from the region of interest (ROI) marked in the STXM optical density image (Figure 4a) are shown in Figure $4 \mathrm{~b}$ and compared with those of amorphous sodium titante (NTO25), anatase $\mathrm{TiO}_{2}$, and crystalline $\mathrm{Na}_{0.23} \mathrm{TiO}_{2}$ (NTO-900). The $\mathrm{Ti} \mathrm{L}_{3,2}$-edge XANES spectra from ROI-1, ROI-2, and ROI-3 show a distinct feature of energy splitting of $b_{1}$ and $b_{2}$ peaks, which is the same as observed in the $\mathrm{Ti}_{3,2}$-edge spectrum of NTO-500 in Figure 3a. the energy positions of $b_{1}$ and $b_{2}$ peaks are aligned with those of anatase $\mathrm{TiO}_{2}$, revealing the dominance of anatase $\mathrm{TiO}_{2}$-like structure in ROI-1, ROI-2, and ROI-3. For ROI-4, ROI-5, ROI-6, and ROI-7, the Ti $\mathrm{L}_{3,2}$-edge XANES spectra exhibit broadened feature in the $\mathrm{b}$ peak, with a hardly noticable $\mathrm{b}_{2}$ at the $\mathrm{Ti} \mathrm{L}_{3}$-edge, which is about $0.2 \mathrm{eV}$ lower than that of $\mathrm{Na}_{0.23} \mathrm{TiO}_{2}$, but in agreement well with that of amorphous sodium titanate. Therefore, the region of ROI-4, ROI-5, ROI-6, and ROI-7 is mainly composed of disordered sodium titanate. STXM chemical maps of anatase $\mathrm{TiO}_{2}$ and 
313 amorphous sodium titanate in NTO-500 are displayed in Figure 4c and 4d, respectively. While

314 anatase $\mathrm{TiO}_{2}$ mainly exisits in the region of ROI-1, ROI-2, and ROI-3, a trace amount of anatase

$315 \mathrm{TiO}_{2}$ appears in ROI-6 and ROI-7 (Figure 4c). The distribution of amorphous sodium titanate in

316 this sample is opposite to anatase $\mathrm{TiO}_{2}$ (Figure 4d). Figure 4e presents the composite map of

317 amorphous sodium titanate (blue) and anatase $\mathrm{TiO}_{2}$ (red) in NTO-500. It is evident that both

318 phases coexist in the region of ROI-3, while anatase $\mathrm{TiO}_{2}$ begins to nucleate in the regions

319 marked by white arrows. The TEM image of the same region (Figure SI-1a) indicates that the

320 tubular structure collapse in ROI-1, ROI-2, and ROI-3, but maintain its shape in ROI-4, ROI-5,

321 ROI-6.The STXM chemical map in Figure 4 clearly shows that the nucleation and growth of

322 anatase $\mathrm{TiO}_{2}$ are non-uniform in the local region of NTO-500, and preferably occurs in the

323 collapsed structure.
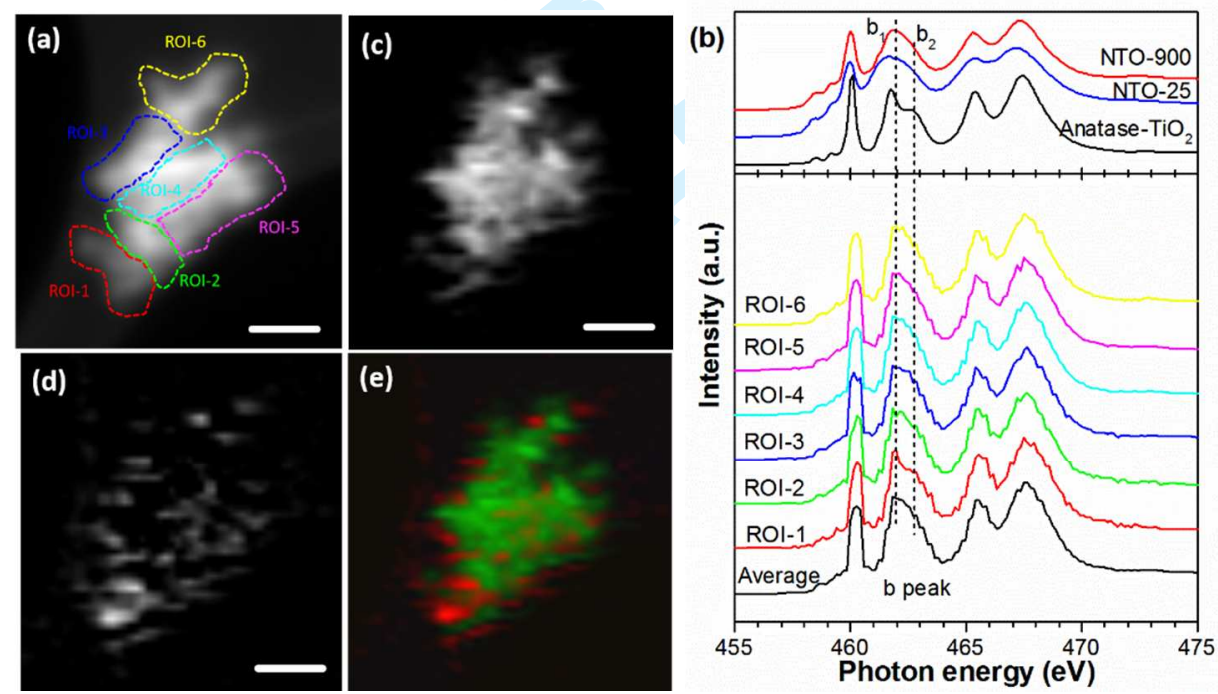

Figure 5. (a) STXM optical density image of NTO-700 (the image was averaged from all

stack images at the Ti $\mathrm{L}_{3,2}$-edge); (b) Ti $\mathrm{L}_{3,2}$-edge XANES spectra extracted from different ROIs

327 in (a) and together with an average spectrum (sum) of these ROIs in comparison with the TEY spectra of anatase $\mathrm{TiO}_{2}$, NTO-25, and NTO-900; STXM chemical mappings of Ti in (c) 
329 330 331

333

334 335 336 337 338 crystalline $\mathrm{Na}_{0.23} \mathrm{TiO}_{2}$, (d) anatase $\mathrm{TiO}_{2}$, and (e) overlap of Ti in crystalline $\mathrm{Na}_{0.23} \mathrm{TiO}_{2}$ (green) and anatase $\mathrm{TiO}_{2}$ (red). The scale bars in (a, c, d, and e) represent $200 \mathrm{~nm}$.

The STXM optical density image of NTO-500 recorded at the Ti $\mathrm{L}_{3,2}$-edge is illustrated in Figure 5a. Ti $\mathrm{L}_{3,2}$-edge XANES spectrum collected from ROI-1 (Figure 5b) exhibits a wellresolved $b$ peak at the $\mathrm{Ti} \mathrm{L}_{3}$-edge, and the intensity ratio of the splitted $b_{1} / b_{2}$ peaks is close to that of anatase $\mathrm{TiO}_{2}$. In contrast, the $\mathrm{Ti} \mathrm{L}_{3,2}$-edge spectra extracted from other ROIs show similarity as $\mathrm{Na}_{0.23} \mathrm{TiO}_{2}$ (NTO-900), and the energy position of $\mathrm{b}$ peak is about $0.2 \mathrm{eV}$ higher than that of amorphous sodium titanate (NTO-25). Chemical maps in Figures 5c and 5d present that $\mathrm{Na}_{0.23} \mathrm{TiO}_{2}$ and anatase $\mathrm{TiO}_{2}$ are distributed across the whole region of NTO-700. The overlapping chemical map in Figure 5e show the mixed distribution of $\mathrm{Na}_{0.23} \mathrm{TiO}_{2}$ (green) and anatase $\mathrm{TiO}_{2}$ (red), between which the boundary can be identified. The STXM analysis in Figure 4 and Figure 5 allow us to visilize the nanoscale phase distribution in sodium titanates at different annealing temperatures.

The detailed analysis by combining in-situ XRD, SEM, XAS, and STXM techniques reveal the phase transition pathway of amorphous to crystalline sodium titanate with annealing temperature. Sodium titanate grown on CNTs shows highly disordered structure at the as-deposited state. At a relative low temperature $\left(500{ }^{\circ} \mathrm{C}\right)$, anatase $\mathrm{TiO}_{2}$ first nucleates and grows in the amorphous sodium titanate, preferably in the collpased region. With the increase of temperature to $700{ }^{\circ} \mathrm{C}$, anatase $\mathrm{TiO}_{2}$ recrystallizes into $\mathrm{Na}_{0.23} \mathrm{TiO}_{2}$ by reacting with sodium in the structure. $\mathrm{TiO}_{2}$ to $\mathrm{Na}_{0.23} \mathrm{TiO}_{2}$ phase transition is relatively slow, and complete in $300 \mathrm{~min}$ at $900{ }^{\circ} \mathrm{C}$. Anatase $\mathrm{TiO}_{2}$ phase is stable even at $900{ }^{\circ} \mathrm{C}$, and does not change to rutile $\mathrm{TiO}_{2}$ phase as generally observed in 
352 pure $\mathrm{TiO}_{2}$ system. ${ }^{29}$ While the influence of alkaline ions on the phase transition temperature of 353 anatase $\mathrm{TiO}_{2}$ to rutile $\mathrm{TiO}_{2}$ is still in debate and totally opposite conclusions have been drawn, 354 our work suggests that the introduction of $\mathrm{Na}^{+}$and sodium titanate improves the thermal stability 355 of anatase $\mathrm{TiO}_{2}$ and therefore increases the phase transition temperature of anatase $\mathrm{TiO}_{2}$ to rutile $356 \mathrm{TiO}_{2}$.

\section{Conclusions}

360 The phase transition mechanism of sodium titanate upon annealing was elucidated by using in361 situ XRD, SEM, XANES, and STXM characterizations. Amorphous sodium titanate was stable 362 at room temperature and crystallized into anatase $\mathrm{TiO}_{2}$ at low annealing temperatures. Anatase $363 \mathrm{TiO}_{2}$ was found to recrystallize into monoclinic $\mathrm{Na}_{0.23} \mathrm{TiO}_{2}$ at $900{ }^{\circ} \mathrm{C}$. STXM chemcial mapping 364 revealed that nuclation and growth of anatase $\mathrm{TiO}_{2}$ was non-uniform in the matrix of amorphous 365 sodium titanate at $500{ }^{\circ} \mathrm{C}$, while the phase transition from anatase $\mathrm{TiO}_{2}$ into $\mathrm{Na}_{0.23} \mathrm{TiO}_{2}$ occurred 366 in the whole structure at $700{ }^{\circ} \mathrm{C}$. Moreover, Ti $\mathrm{L}_{3,2}$-edge and K-edge XANES studies revealed 367 that Ti oxidation state in sodium titanate increased during the annealing process.

\section{Acknowledgements}

370 This work was supported by Nature Sciences and Engineering Research Council of Canada 371 (NSERC) program, Canada Research Chair (CRC) Program, Canada Foundation for Innovation 372 (CFI), Ontario Research Fund (ORF), the Canada Light Source (CLS) at the University of 373 Saskatchewan, and the University of Western Ontario. We would like to thank Dr. Ning Cheng 374 at CLS for his strong support on HXMA data acquisition and interpretation. 


\section{References}

383

(1) Senguttuvan, P.; Rousse, G.; Seznec, V.; Tarascon, J.-M.; Palacín, M.R. Chem. Mater. 2011, 23, 4109. DOI: $\underline{10.1021 / \mathrm{cm} 202076 \mathrm{~g}}$

(2) Wu, D.; Li, X.; Xu, B.; Twu, N.; Liu, L.; Ceder, G. Energy Environ. Sci. 2015, 8, 195. DOI: $\underline{10.1039 / \mathrm{C} 4 \mathrm{EE} 03045 \mathrm{~A}}$

387

388

(3) Pan, H.; Lu, X.; Yu, X.; Hu, Y.-S.; Li, H.; Yang, X.-Q.; Chen, L. Adv. Energy Mater. 2013, 3, 1186. DOI: $\underline{10.1002 / \mathrm{aenm} .201300139}$

(4) Štengl, V.; Bakardjieva, S.; Šubrt, J.; Večerníková, E.; Szatmary, L.; Klementová, M.; Balek, V. Appl. Catal. B-Environ. 2006, 63, 20. DOI:10.1016/j.apcatb.2005.09.006

(5) Song, H.; Jiang, H.; Liu, T.; Liu, X.; Meng, G. Mater. Res. Bull. 2007, 42, 334. DOI: $\underline{10.1016 / \text { j.materresbull.2006.05.025 }}$

(6) EI-Naggar, I.M.;Mowafy, E.-A.; Ali, I.M.; Aly, H.F. J. Int. Adsorp. Soc. 2002, 8, 225. DOI: $\underline{10.1023 / \mathrm{A}: 1021212617839}$

395

(7) Liu J.; Banis, M.N.; Xiao, B.; Sun, Q.; Lushington, A.; Li, R.; Guo, J.; Sham, T.-K.; X. Sun. J. Mater. Chem. A 2015, 3, 24281. DOI: $\underline{10.1039 / C 5 T A 08435 K}$ 
397

398

399

400

401

402

403

404

405

406

407

408

409

410

411

412

413

414

415

416

417

418

(8) Li, M.-J.; Chi, Z.-Y.; Wu, Y.-C. J. Am. Ceram. Soc. 2012, 95, 3297. DOI: 10.1111/j.1551$\underline{2916.2012 .05330 . x}$

(9) Zárate, R.A.; Fuentes, S.; Wiff, J.P.; Fuenzalida, V.M.; Cabrera, A.L. J. Phys. Chem. Solids 2017, 68, 628. DOI: $10.1016 /$ j.jpcs.2007.02.011

(10) Viana, B.C.; Ferreira, O.P.; Filho, A.G.S.; Filho, J.M.; Alves, O.L. J. Braz. Chem. Soc. 2009, 20, 167. DOI: $\underline{\text { http://dx.doi.org/10.1590/S0103-50532009000100025 }}$

(11) Tsai, C.C.; Teng, H. Chem. Mater. 2006, 18, 367. DOI: $\underline{10.1021 / \mathrm{cm} 0518527}$

(12) Yang, J.; Jin, Z.; Wang, X.; Li, W.; Zhang, J.; Zhang, S.; Guo, X.; Zhang, Z. Dalton Trans. 2003, 20, 3898. DOI: $\underline{\text { 10.1039/B305585J }}$

(13) Zhu, K.R.; Yuan, Y.; Zhang, M.S.; Hong, J.M.; Deng, T.; Yin, Z. Solid State Commun. 2007, 144, 450. DOI: $10.1016 /$ j.ssc.2007.09.015

(14) Sun, X.; Li, Y. Chem. Eur. J. 2003, 9, 2229. DOI: 10.1002/chem.200204394

(15) Papp, S.; Korosi. L.; Meynen, V.; Cool, P.; Vansant, E.F.; Dekany, I. J. Solid State Chem. 2005, 178, 1614. DOI:10.1016/j.jssc.2005.03.001

(16) Li, J.; Wang, Z.; Zhao, A.; Wang, J.; Song, Y.; Sham, T.-K. J. Phys. Chem. C. 2015, 119, 17848. DOI: $\underline{10.1021 / \text { acs.jpcc.5b04276 }}$

(17) Zhou, J.G.; Fang, H.T.; Maley, J.M.; Murphy. M.W.; Peter Ko J.Y.; Cutler, J.N.; Sammynaiken, R.; Sham, T.-K.; Liu, M.; Li, F. J. Mater. Chem. 2009, 19, 6804. DOI: $\underline{10.1039 / \mathrm{B} 909225 \mathrm{~K}}$

(18) Pearson, A.L.; Chao, W.L.; Denbeaux, G.; Eimuller, T.; Fischer, P.; Johnson, L.; Koehler, M.; Larabell, C.; Le Gros, M.; Yager, D.; Attwood, D.T. Proc. SPIE 2000, 4146, 54. DOI: $\underline{10.1117 / 12.406672}$ 
419 (19) Wang, Z.Q.; Wang, W.; Sham, T.K.; Yang, S.G. Nanoscale 2014, 6, 9783. DOI: $420 \quad \underline{10.1039 / C 4 N R 02231 \mathrm{~A}}$

421 (20) Henderson, G.S.; Liu, X.; Fleet, M.E. Phys. Chem. Minerals 2002, 29, 32. DOI: $422 \quad \underline{10.1007 / \mathrm{s} 002690100208}$

423 (21) Kucheyev, S.O.; van Buuren, T.; Baumann, T.F.; Satcher, J.H.; Willey, T.M.; 424 Meulenberg, R.W.; Felter, T.E.; Poco, J.F.; Gammon, S.A.; Terminello, L.J. Phys. Rev. B 425 426 427 428 429 430 431 432 2004, 69, 245102. DOI: $10.1103 /$ PhysRevB.69.245102

(22) Wang, D.; Liu, J.; Sun, X.; Sham, T.-K. J. Mater. Chem. A 2015, 3, 412. DOI: $\underline{10.1039 / \mathrm{C} 4 \mathrm{TA} 04873 \mathrm{C}}$

(23) Wagemaker, M.; Lützenkirchen-Hecht, D.;van Well, A.A.; Frahm, R. J. Phys. Chem. B 2004, 108, 12456. DOI: $\underline{10.1021 / \mathrm{jp} 048567 \mathrm{f}}$

(24) Borghols, W.J.H.; Lützenkirchen-Hecht, D.; Haake, U.; van Eck, E.R.H.; Muldera, F.M.; Wagemaker, M. Phys. Chem. Chem. Phys. 2009, 11, 5742. DOI: $\underline{10.1039 / B 823142 G}$

(25) Nakahira, A.; Kubo, T.; Numako, C. Appl. Mater. Interfaces 2010, 2, 2611. DOI: $\underline{10.1021 / \mathrm{am} 1004442}$

(26) Avansi, Jr. W.; Arenal, R.; de Mendoca, V.R.; Ribeiro, C.; Longo, E. CrystEngComm 2014, 16, 5021. DOI: $\underline{10.1039 / \mathrm{C} 3 \mathrm{CE} 42356 \mathrm{E}}$

(27) Zhou, J.G.; Wang, J.; Liu, Hao.; Banis, M.N.; Sun, X.; Sham, T.-K. J. Phys. Chem. Lett. 2010, 1, 1709. DOI: $\underline{10.1021 / j z 100376 v}$

438 (28) Wang, J.; Zhou, J.; Hu, Y.; Regier, T. Energy Environ. Sci. 2013, 6, 926. DOI: 439 $\underline{10.1039 / \mathrm{C} 2 \mathrm{EE} 23844 \mathrm{~F}}$

440 (29) Hanaor, D.A.H.; Sorrell, C.C. J. Mater. Sci. 2011, 46, 855. DOI: 10.1007/s10853-010$441 \quad \underline{5113-0}$ 

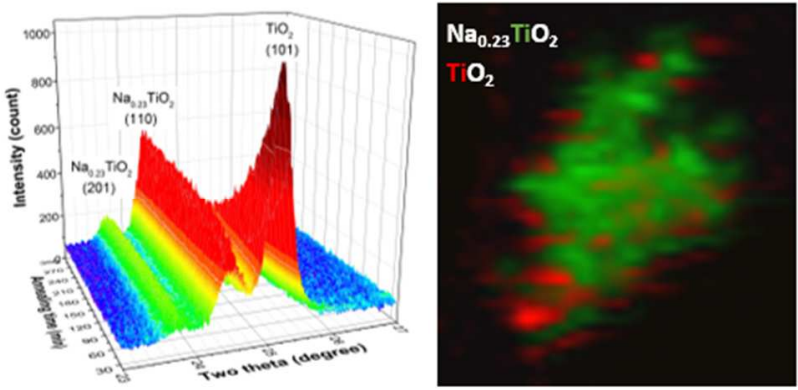